\title{
KNOWLEDGE, ATTITUDE, AND PRACTICES OF EXCLUSIVE BREASTFEEDING: A FACILITY BASED STUDY IN ADDIS ABABA
}

\author{
Tsegalem Hailemariam Ballo ${ }^{1}$, Meaza Zeleke Wodajo ${ }^{2}$, J.SiruMalar ${ }^{3}$ \\ ${ }^{1}$ Department of Nursing, College of Health sciences, Mekelle University, \\ P.O. Box 1871, Mekelle, Ethiopia, \\ ${ }^{2}$ Betele Teaching Hospital, Addis Ababa, Ethiopia \\ ${ }^{3}$ Dept. of Psychiatric Mental health Nursing, College of Health Science, \\ Mekelle University, Mekelle, Ethiopia. \\ P.O. Box 1871, Mekelle, Ethiopia
}

\begin{abstract}
Background: Exclusive breastfeeding of babies for 6 months, as recommended by the World Health Organization, remains a well-recognized childhood survival strategy of great benefit in reducing infant and under-5 mortality rates. Children in Ethiopia suffer from poor health. The national Under-five Mortality Rate is about 140/1000, with variations among the regions from 114 to $233 / 1000$. About $90 \%$ of mortality in underfives was caused by pneumonia, neonatal causes (prematurity, asphyxia and neonatal sepsis), malaria, diarrhea and measles. Malnutrition is the underlying cause of death in about $57 \%$ of these deaths.
\end{abstract}

Method: Facility based cross sectional study was done. Three hundred seventy five mothers' included in the study. A selected mother from private and public facilities with six months live infants interviewed through phone through structured questioner. Mothers delivered in the same month or batch for 6 months after delivery were included for the study. Expression of breast milk awareness, skill, and other determinate factors for EBF was included in the questioner. The data entered and analyzed through SPSS version 20. The data analyzed and their strength of association measured through Chi Squire and Pearson correlation for continuous variables.

Result: The outcome of the study demonstrated that Timely initiation of breastfeeding has correlation significance with mothers who teach on breast-feeding (Pearson correlation=0.12 at $P$ value $=0.05$ ). Most of mother's items had a mean score indicating that most of the mothers had positive attitude on breast feeding. Only $30.5 \%$ of mothers had ever exclusively breastfed. No significance association found between mothers with occupational status and Exclusive breast-feeding practice.

Conclusion: - The Survey shows low exclusive breast-feeding rate. Almost, mothers included in the study, $40 \%$ of them attend deliveries in private hospitals have Caesarean section and these newborns supplemented with formula during the first few days after birth. Knowledge on Expression has positive influence on EBF practice. Health professionals' works in the study area have need-updated knowledge related to Expression of Breast milk.

Key words:

Exclusive breast feeding, Determinant factor for breast-feeding, Breast feeding Knowledge, Attitude and practice, Expression of breast milk.

\section{INTRODUCTION}

According to the Ethiopian demographic health Survey (EDHS) in 2011, 52 percent of children under six months and 32 percent of children 4-5 months are exclusively breastfed, and 75 percent

*Corresponding author:

Email: tsegalemhailemariamb@gmail.com http://dx.doi.org/10.20530/IJTA 33 72-82

ISSN 2320-138X @ 2016 of children under-six months are predominantly breastfed. About half of children ages 6-8 months (49 percent) consume solid, semi-solid, or soft foods. The 24-hour recall method was use in this survey. According to this method even, a child who had other foods, but only breastfed within 24 hours of inquiry, considered exclusively breastfed; this definitely overestimates the actual rates (7). The 24-hour recalls method shown to produce overestimations of the prevalence of exclusive breastfeeding. Developed countries like Australia 
use point in time data for measurement of exclusive breastfeeding. The low prevalence of EBF in most developing countries including Ethiopia attributed to various maternal and child factors. These include place of residence, age, mother working outside home, maternal age and educational level, access to mass media cultural and economic status (5).

Table 1 Child age and delivery history related characteristics $(n=375)$

\begin{tabular}{|c|c|c|}
\hline \multicolumn{2}{|c|}{ Characteristics } & \multirow{2}{*}{$\begin{array}{c}\begin{array}{c}\text { Number } \\
\text { (\%) }\end{array} \\
307(82.0)\end{array}$} \\
\hline Child age & at 6month & \\
\hline & 6-7months & 68 (18.0) \\
\hline \multirow{3}{*}{$\begin{array}{l}\text { Mode of } \\
\text { Delivery }\end{array}$} & SVD & $237(63.2)$ \\
\hline & Elective $\mathrm{C} / \mathrm{S}$ & $95(25.3)$ \\
\hline & $\begin{array}{c}\text { Emergency } \\
\mathrm{C} / \mathrm{S}\end{array}$ & $43(11.5)$ \\
\hline \multirow[t]{2}{*}{$\begin{array}{l}\text { Type of } \\
\text { Institution }\end{array}$} & $\begin{array}{l}\text { Government } \\
\text { Health center }\end{array}$ & $180(48.0)$ \\
\hline & $\begin{array}{l}\text { Private } \\
\text { hospital }\end{array}$ & 195 (52.0) \\
\hline \multicolumn{3}{|c|}{$\begin{array}{l}\text { The mean age of mothers was } 28.7 \text { years at the time } \\
\text { of survey. Near to half of the mothers }(46.9 \% \\
\text { completed secondary school and the rest hac } \\
\text { diploma and above. One hundred sixty eight ( } 44.8 \% \\
\text { worked for government or private institution. }\end{array}$} \\
\hline
\end{tabular}

There are a number of interventions in use around breastfeeding, ranging from international conventions to working with individual mothers and families, and which use a wide range of tools (4). Education is therefore a critical component of any strategy to support, promote and protect breastfeeding (4). Exclusive breast-feeding is adequate in quality as well as quantity in terms of energy, protein, nutrients, water etc. for an infant's need under six months of age.

Maternal employment, inadequate support by health professionals in maternity hospitals and clinics, inadequate prenatal and postnatal breastfeeding education, negative attitudes of mothers toward breastfeeding as well as lack of support from expectant fathers are barriers to initiating and sustaining breastfeeding (6).Lack of knowledge was the main barrier of exclusive breastfeeding. Working mothers were more likely not to exclusively breastfeed their babies. Attitude was a predictor of feeding choice and duration of exclusive and partial breastfeeding, and was not restricted to pregnant women or mothers (8).Knowledge, attitudes and practices associated with infant and young child feeding essential first step for any need-felt for an intervention program designed to bring about positive behavioral change in infant health and feeding option (20).

This study assessed KAP and determinant factors of exclusive breast-feeding on point in time data collection from mothers attended their last delivery in health facility.

\section{Methods \\ Study Design}

The study conducted in Addis Ababa the capital of Ethiopia. The city divided into 10 sub cities. The 10 sub cities have 41 hospitals and 128 health centers. Public and the rest run by private investors and non-profit organizations. Three private and public facilities selected for the study, which are from private Girum, bethel and Betsegah hospital. From Public facilities, Beleteshachew, kirkose, Meshulekia health centers. The private facilities selected from the rest one was due to their pioneer for delivery service and for public facilities selected from 10 sub cities by lottery method. Ledeta and kirkose sub city identified after that health centers selected depended on availability of mothers Phone number on medical record.

\section{Sampling procedure}

Private hospitals selected than private clinics because of most of delivery service given in private hospitals than private clinics. On parallel public health centers, run delivery service for every mother on their catchment area and the public hospitals accomplished delivery service for mothers who have indication for referral from health centers. So for every mother entry point are health centers for delivery service. Mothers With same batch for delivery date of the last baby captured from delivery register and from Individual medical record, we take their phone number. During our data collection For February 21 /2007 E.C we take mother delivered six month back that was $17 / 12 / 2006 \mathrm{E}$.C with this method we get the mothers included for the study. All mother from private hospital have phone number but not public. For that reason, public facilities include for the study one hundred eighty mother but the private clinics one hundred ninety five. The mothers interviewed through structured via phone in average 10- 15 minutes questioner. The study used convenience non-probability sampling technique. The data collectors trained for 2 days. To be confidential data collectors was health 
Table. 2 Socio demographic characteristics of respondent

\begin{tabular}{|c|c|c|}
\hline Demographic Characteristics & Number & $\begin{array}{c}\text { Percent } \\
\text { (\%) }\end{array}$ \\
\hline \multicolumn{3}{|l|}{ Maternal Age ( $\mathrm{N}=375$ ) } \\
\hline$<=24$ & 38 & 10.1 \\
\hline 25-29 & 185 & 49.3 \\
\hline $30-34$ & 121 & 32.3 \\
\hline$>=35$ & 31 & 8.3 \\
\hline Mean age & 28.7 & \\
\hline \multicolumn{3}{|l|}{$\begin{array}{l}\text { Maternal Education } \\
(\mathrm{N}=375)\end{array}$} \\
\hline illiterate & 18 & 4.8 \\
\hline Primary and secondary & 176 & 46.9 \\
\hline Diploma & 122 & 32.5 \\
\hline Degree and above & 59 & 15.7 \\
\hline
\end{tabular}

\section{Paternal Education}

$(\mathrm{N}=354)$

$\begin{array}{rcc}\text { illiterate } & 6 & 1.6 \\ \text { Primary and secondary } & 93 & 24.8 \\ \text { Diploma } & 118 & 31.5 \\ \text { Degree and above } & 137 & 36.5\end{array}$

\section{Maternal Occupation}

$(\mathrm{N}=373$ )

\begin{tabular}{|c|c|c|}
\hline Employed & 168 & 44.8 \\
\hline Private business & 97 & 25.9 \\
\hline House wife & 108 & 28.8 \\
\hline \multicolumn{3}{|l|}{ Family Income ( $\mathrm{N}=281$ ) } \\
\hline$<4500$ & 150 & 53.4 \\
\hline $4500-10000$ & 87 & 31 \\
\hline$>10000$ & 44 & 15.7 \\
\hline Mean & 5705 & \\
\hline
\end{tabular}

professionals (nurse or midwife) who work in the study facility delivery room. Data collection was preceded with a pilot survey.

\section{Data collection and analysis}

The questionnaires have six parts of questions. These are Demographic data gravidity and parity history, exclusive breastfeeding queries, knowledge on breastfeeding, breast-feeding attitude and practice of expressing breast milk. Mothers with their infants were the same batch of 6 months gone through for data collection. A sample size of 384 is calculated using single population proportion. EDHS 2011 the proportion of exclusive breast-feeding is $52 \%$, with a precision level $5 \%$ and $95 \%$ confidence interval (20).

The Knowledge of mother's toward breast-feeding questionnaire items testing included recommended breastfeeding initiation and duration, Complete information for breast feeding benefit (child and maternal), and history of health education about breast-feeding.

The three-point type lowa Infant Feeding Attitude Scale (IIFAS) was used for rating the mother's 
attitudes. The lowa Infant Feeding attitude Scale is one of the measurements that has sufficient evidence of its reliability and validity in investigating the association between attitude and breastfeeding (3).Three levels scale for mothers attitudes as for agree, neutral, disagree levels respectively. Questions that evaluated mothers' attitude included Formula feeding is more convenient than breastfeeding, Breastfeeding increases mother infant bonding, breast-feeding is mandatory, and Breastfed babies are healthier than formula fed babies. Data entry and analysis was done using SPSS statistical package version 20. The Chi Squire Test will use to check for strength of association between variables at the $95 \%$ confidence level.

\section{Ethical Consideration}

Ethical clearance for the study was obtained from Addis Ababa university school of public health Ethical Committee Participants received verbal information by phone about the purpose and advantageous of the study. There were no predicted physical, social or legal risks associated with participation. Interviews were conducted after the respondents gave verbal consent.

Table 3 Breastfeeding knowledge assessment questions response

\begin{tabular}{lcc}
\hline $\begin{array}{c}\text { Breast feeding knowledge } \\
\text { assessment queries }\end{array}$ & $\begin{array}{c}\text { Correct } \\
\text { Reponses }\end{array}$ & $\begin{array}{c}\text { Number } \\
\text { (\%) }\end{array}$ \\
\hline $\begin{array}{l}\text { Mothers who teach on } \\
\text { breast feeding from health } \\
\text { professionals }\end{array}$ & Yes & 224(59.7) \\
$\begin{array}{l}\text { The right time to initiate } \\
\text { breast feeding }\end{array}$ & no & 110(32.7) \\
& yes & 223(67.26) \\
$\begin{array}{l}\text { The optimal duration of } \\
\text { breastfeeding an infant }\end{array}$ & no & 268(78.5) \\
& yes & $73(21.4)$ \\
\hline $\begin{array}{l}\text { Complete information on } \\
\text { breast feeding benefit }\end{array}$ & All & $77(20.5)$ \\
\hline
\end{tabular}

\section{RESULTS}

\section{Characteristics of respondents}

The total number of respondent mothers was 375 (Table $1 \& 2$ ). This gives a response rate of $89.3 \%$. Most of them 307 (82.0\%) had a child of age 6 months. Two hundred thirty seven (63.2\%) of the babies were born via Spontaneous Vaginal Delivery (SVD) while 95 (25.3\%) were delivered by elective caesarean section $(C / S)$. About equal number of the deliveries were made at public and private health facilities.

\section{Knowledge of exclusive breastfeeding}

Knowledge of mothers on breastfeeding assessed by different parameters mentioned on Table 3 . Two hundred twenty six (67.3\%) of the respondents knew about timely initiation of breastfeeding. Timely initiation of breastfeeding is significantly associated with getting education on breastfeeding. (Pearson chi square=10 and $P$ value $=0.01$ ). Mothers with complete information on breast-feeding benefits (such as time initiation, course and advantageous breast-feeding) were 77 (20.5\%). Pearson's chi square analysis revealed a positive and significant association between educational levels of the mother $(P<0.01)$ and breastfeeding knowledge.

\section{Attitudes of exclusive breastfeeding}

Most of the mother have positive attitude on breastfeeding and not accept formula feeding. Early initiation also good and most mothers think breast-feeding mandatory (Table 4).

\section{Practices of breastfeeding}

The rate of initiation of breastfeeding after birth was $87.2 \%$. Out of the 375 mothers surveyed, 260 (70\%) reported that they feed their baby other than breast milk and 48 (12.8\%) reported that they never began breastfeeding. Only one hundred fourteen $(30.5 \%)$ of mothers had ever exclusively breastfed.

\section{Knowledge on expression of breast Milk}

From 375 mothers two hundred eighty-eight (72\%) of them do not have knowledge on expression of breast milk. Correlation illustrate mothers with expression knowledge has more number on exclusive breast-feeding practice (Pearson $X^{2}=0.3$ at $P V=0.028$ ) so mothers who express milk has optimistic relation between exclusive breast feeding practice. Finding shows only eighty-five (22.8\%) of mothers have knowledge on Expression and hear about it $43(54 \%)$ from relatives 19 (5\%) of it only know from health professionals. Most mothers sixty-four (80\%) use hand pump next manual expression method. Statistical significance shows Pearson Chi Square 11.9 at $\mathrm{P}$ Value < 0.01 between Institution type and expressing breast milk. 
Association of Knowledge and practice of breastfeeding with socio-demographic characteristics Knowledge of benefit of breast milk and maternal education, has statically significant relation (Table 5) (Pearson chi Square $=9.8$ at $P$ value $=0.02$ ) Therefore, knowledge of the benefits of EBF increased with an increase of education level from illiterate to higher educational level. Feeding babies other than breast milk is different depending on the place of delivery. Women giving birth in public facilities are more likely to feed their babies breast milk compared to those who delivered in public facilities $\left(X^{2}=10.2\right.$, P-Value $<0.01$ ). Pearson Chi Square shows association between type of family, educational level of mother, type of delivery, occupational status of the mother and practice at $P$-Value $<0.01$, nevertheless no any association educational level of father and EBF.

\section{DISCUSSION}

The superiority of breast milk (BM) over any other milk nourishment of the human newborn and infant can hardly be challenged, and over the years. Regrettably, despite the enormous benefits of breast milk, the decline of EBF persists in many developing countries (12). Efforts made to

Table. 4 Mother's IIFAS items distribution on Attitude

\begin{tabular}{|c|c|c|c|}
\hline & Agree & Neutral & Disagree \\
\hline $\begin{array}{l}\text { breast feeding is } \\
\text { mandatory }\end{array}$ & 70.4 & 0 & 29.6 \\
\hline $\begin{array}{l}\text { Formula feeding } \\
\text { is more } \\
\text { convenient than } \\
\text { breastfeeding }\end{array}$ & 45.87 & 1.87 & 52.27 \\
\hline $\begin{array}{l}\text { Breastfeeding } \\
\text { increases } \\
\text { mother infant } \\
\text { bonding }\end{array}$ & 48.46 & 17.62 & 33.92 \\
\hline
\end{tabular}

\begin{tabular}{|c|c|c|}
\hline $\begin{array}{l}\text { Breastfed babies } \\
\text { are healthier } \\
\text { than formula } \\
\text { fed babies }\end{array}$ & 87.7 & 0.8 \\
\hline
\end{tabular}

promote BM use in the past few years, have been encouraging and noteworthy to see mothers changed to EBF in developed countries. Paradoxically enough, this unfavorable trend is noticeable in poor countries where the supply of artificial milk is scarce (19). In this study, conducted in Addis Ababa facilities from mothers who attended their recent baby delivery in the institution, a high percentage of mothers (87.2\%) had initiated breastfeeding on time. Although a high proportion of mothers initiated breastfeeding, the exclusive breastfeeding rate and the duration of breastfeeding were far below WHO and national recommendations. The large differences in the results may be due to the use of different methodology for data collection. One of the reasons of low exclusive breastfeeding in Addis Ababa may be the comprehensive emergency care intervention widely accomplished. Our study found $36.8 \%$ deliveries attended by caesarian section so mothers had difficulties to breast feed due to wound site pain (18). Maternal education level,maternal age, and family income were positively correlated with Exclusive breast-feeding practice. Paternal educational and exclusive breastfeeding did not show any significant association these contrary result obtained from the Ethiopian demographic health survey, which indicated a declining trend of exclusive breastfeeding practice with the higher maternal education status(23). Mothers from lower socioeconomic status breastfed longer because they could not afford formula milk especially mother deliver by caesarian section due to wound site pain most babies start feeding from formula milk. To reduce this detracting influence on EBF practice, measures should take to reduce deliveries by non-vaginal routes and adopt protocols that minimize Caesarean pain and other co-morbidities when inevitably indicated. This way, the temptation to use prelacteal feeds and subsequent non-EBF practice will be pointed (18).

The way respondents know about breast-feeding from health professionals on recommendation of the optimal duration of breastfeeding varies. This indicates focus given on breastfeeding counseling by health professionals so that the mothers can get adequate information and the lack of uniform recommendations from health professionals. Knowledge of the mothers about exclusive breastfeeding practices is not associated with their practice, which is contrary to the finding in the study done in Tanzania, Kilimanjaro region, where women not having knowledge on exclusive breastfeeding are more likely to terminate exclusive breastfeeding early (20). Knowledge of EBF concept was very high but its practice was distinctly lagging. It was evident from current study that awareness and knowledge do not 
equate to practice. Inferentially, our mothers, probably, have not come to accept or understand the critical vital benefit of EBF or that the challenges to its practice are consider insurmountable for now. To overcome this, emphasis should be shift from mere dissemination of information on EBF to empirically helping mothers resolve potential challenges highlighted in this study. The unacceptably low rates of EBF seen in this study make it imperative that attitudeleveraging measures established that Implement to optimize the benefits from proper breastfeeding practices.

This study shows positive attitudes are positively associated with increased duration of exclusive breastfeeding. In addition, other study also shows that breastfeeding education can positively affect attitudes, and intentions to breastfeed (4). Expression allows a mother some independence from directly feeding her infant and may allow her to return to work or undertake some social activities while continuing to breastfeed. This study showed that expressing breast milk is not common. Only $22.8 \%$ of mothers have knowledge and heard about expression of BM 54\% from relatives $19 \%$ of it only know from health professionals. Health professionals are responsible the teaching of hand expression and knowledgeable of the breast pump technologies available (26). In the study, $80 \%$ of mothers use breast pump, which may not show their type and all mothers' expression not more than six months.

Table. 5 Analysis result of association between KAP and socio demographic factor

\begin{tabular}{lrr}
\hline $\begin{array}{l}\text { Socio demographic } \\
\text { Characteristics }\end{array}$ & \multicolumn{1}{c}{$\begin{array}{c}\text { Association } \\
\text { with } \\
\text { Knowledge }\end{array}$} & $\begin{array}{c}\text { Association } \\
\text { with Practice }\end{array}$ \\
\cline { 2 - 3 } $\begin{array}{c}\text { Pearson Chi } \\
\text { square }\end{array}$ & $\begin{array}{c}\text { Pearson Chi } \\
\text { square }\end{array}$ \\
\hline Maternal Age & 0.03 & $-0.2^{* *}$ \\
\hline $\begin{array}{l}\text { Maternal } \\
\text { Education }\end{array}$ & $9.8^{* *}$ & $14^{* *}$ \\
\hline Paternal Education & 9.5 & $10.4^{* *}$ \\
\hline Mode of Delivery & 14.5 & $87^{* *}$ \\
\hline Type of institution & 4.2 & $11.9^{* *}$ \\
\hline Family Income & 236.1 & $-0.4^{* *}$ \\
\hline
\end{tabular}

** Significant at $95 \%$ confidence interval for education programs need both to be skilled in Hand expressing contributes to less awkwardness or embarrassment for the mother, who is more likely to be comfortable hand expressing than using a pump when others are present (28). The correlation shows significant association between a mother with expression knowledge and exclusive breast-feeding practice and type of institution of delivery.

\section{CONCLUSION}

This point in time method of exclusive breastfeeding study shows type of family, educational level of mother and father, type of delivery has relation with Exclusive breast-feeding. In addition, findings show mothers who attend their deliveries and have information on breast-feeding have low exclusive breast-feeding rate. In Ethiopia, compared with last version of Ethiopian demographic health survey (2011) result, almost5yrs ago, decline in EBF practice. These could be EDHS uses 24-hour recall data collection for mothers with under two years children. Almost, mothers included in the study, $40 \%$ of them attend deliveries in private hospitals have Caesarean section and these newborns supplemented with formula during the first few days after birth. Moreover, we found that our private hospitals did not adhere to WHO statement "Ten steps to successful breastfeeding", which might have unfavorable influence on Exclusive breast-feeding. Knowledge on Expression has positive influence on EBF practice but More of Mothers not hear about it from health professionals so need to give updated information about means of expression of breast milk.

\section{LIST OF ACRONYMS}

EBF Exclusive Breast Feeding

EBM Expressed Breast Milk

BF Breast Feeding

KAP Knowledge, Attitude and Practice

MDG Millennium Development Goal

HSDP Health Sector Development Plan

EDHS Ethiopian Demographic Health Survey

WHO World Health Organization

SPSS Statistical Package for the Social Sciences

IIFAS lowa Infant Feeding Attitude Scale

BCC Behavioral change communication

KAP Knowledge, Attitude and practice

\section{Competing interests}

The authors declare that there is no competing of interests. 


\section{ACKNOWLEDGMENT}

Our heartfelt gratitude is go to our friends and family who provided support and enormous encouragement throughout this work. We would also like to thank Addis Ababa health Bureau for permitting and supporting letter, which addresses sub cities. Ledeta and kirkose subcities, Girum, Betsegahe and Bethel Hospital appreciated for their contribution and collaboration in producing my survey. Also we would like to thank Ethiopian Public Health Association (EPHA) for their encouragement. Finally, and most importantly we would like to acknowledge the study participants for providing me their keen response.

We need to publish this thesis to disseminate the results to the public and to provide awareness about the Knowledge, attitude, and practices of exclusive breastfeeding.

\section{REFRENCES}

1. Infant and child feeding. Organisation for Economic Co-Operation and Development (OECD); Available from: http://dx.doi.org/10.1787/888933152 $\underline{664}$

2. Kramer MS, Kakuma R. Optimal duration of exclusive breastfeeding. Kramer MS, editor. Reviews; 2012 Aug 15; Available from: http://dx.doi.org/10.1002/14651858.c d003517.pub2

3. Chen W. Breastfeeding knowledge, attitude, practice and related determinants among mothers in Guangzhou, China. The University of Hong Kong Libraries; Available from: http://dx.doi.org/10.5353/th b45171 $\underline{02}$

4. Jones S. Protecting, Promoting And Supporting Breastfeeding: The Handbook of the New Zealand College of Midwives. Journal of Human Lactation;10(3):204-5. Available from: http://dx.doi.org/10.1177/089033449 $\underline{401000326}$

5. Hormann E. Infant and Young Child Feeding: Challenges to Implementing a Global Strategy. Birth; 2011 Nov 23;38(4):364-5. Available from: http://dx.doi.org/10.1111/j.1523536x.2011.00503 2.x

6. Sefene A. Determinants of Exclusive Breastfeeding Practice among Mothers of Children Age Less Than 6 Month in Bahir Dar City Administration, Northwest Ethiopia; A Community Based Cross-Sectional Survey. Science Journal of Clinical Medicine; 2013;2(6):153. Available from:

http://dx.doi.org/10.11648/j.sjcm.201 $\underline{30206.12}$

7. Dyson L, Renfrew MJ, McFadden A, McCormick F, Herbert G, Thomas J. Policy and public health recommendations to promote the initiation and duration of breastfeeding in developed country settings. Public Health Nutrition; 2009 Aug 18;13(01):137. Available from: http://dx.doi.org/10.1017/s13689800 $\underline{0999067 x}$

8. Perera PJ, Fernando $M$, Warnakulasuria $\mathrm{T}$, Ranathunga $\mathrm{N}$. Feeding practices among children attending child welfare clinics in Ragama $\mathrm{MOH}$ area: a descriptive cross-sectional study. International Breastfeeding Journal; 2011;6(1):18. Available from: http://dx.doi.org/10.1186/1746-43586-18

9. Meedya S, Fahy K, Kable A. Factors that positively influence breastfeeding 
duration to 6 months: A literature review. Women and Birth; 2010 Dec;23(4):135-45. Available from: http://dx.doi.org/10.1016/j.wombi.20 $\underline{10.02 .002}$

10. Kazembe L. Spatial Modelling of Initiation and Duration of Breastfeeding: Analysis of Breastfeeding Behaviour in Malawi - I. World Health \& Population; 2009 Jan 15;10(3):47-64. Available from: http://dx.doi.org/10.12927/whp.2009 .20523

11. Zamora G, Lutter CK, Pena-Rosas JP. Using an Equity Lens in the Implementation of Interventions to Protect, Promote, and Support Optimal Breastfeeding Practices. Journal of Human Lactation; 2014 Dec 8;31(1):21-5. Available from: http://dx.doi.org/10.1177/089033441 $\underline{4561477}$

12. Chowdhury HA, Ahmed KR, Jebunessa F, Akter J, Hossain S, Shahjahan M. Factors associated with maternal anaemia among pregnant women in Dhaka city. BMC Women's Health; 2015 Sep 22;15(1). Available from: http://dx.doi.org/10.1186/s12905$\underline{015-0234-x}$

13. Nkonki LL, Daviaud E, Jackson D, Chola L, Doherty T, Chopra M, et al. Costs of Promoting Exclusive Breastfeeding at Community Level in Three Sites in South Africa. Newell M-L, editor. PLOS ONE 10;9(1):e79784. Available from: http://dx.doi.org/10.1371/journal.pone.0 $\underline{079784}$
14. Perera PJ, Ranathunga N, Fernando MP, Sampath W, Samaranayake GB. Actual exclusive breastfeeding rates and determinants among a cohort of children living in Gampaha district Sri Lanka: A prospective observational study. International Breastfeeding Journal ; 2012;7(1):21. Available from: http://dx.doi.org/10.1186/1746-43587-21

15. Worcester J. Pathways to competence: Encouraging healthy social and emotional development in young children. Infant Ment Health J; 2005 Jan;26(1):85-7. Available from: http://dx.doi.org/10.1002/imhi.20030

16. Ezra M, Gurum E. Breastfeeding, birth intervals and child survival: Analysis of the 1997 community and family survey data in southern Ethiopia. Ethiopian Journal of Health Development ; 2002 Jan 1;16(1). Available from: http://dx.doi.org/10.4314/ejhd.v16i1. $\underline{9825}$

17. Ku C-M, Chow SK. Factors influencing the practice of exclusive breastfeeding among Hong Kong Chinese women: a questionnaire survey. Journal of Clinical Nursing; 2010 Aug 15;19(1718):2434-45. Available from: http://dx.doi.org/10.1111/j.13652702.2010.03302.x

18. CI CE. Exclusive Breastfeeding Practice and Associated Maternal SocioDemographic Factors among Mothers Attending Imo State Specialist Hospital, Owerri, South-Eastern Nigeria. Arch Community Med Public Health; 027-31. Available from: http://dx.doi.org/10.17352/2455$\underline{5479.000013}$ 
19. Alemayehu T, Haidar J, Habte D. Determinants of exclusive breastfeeding practices in Ethiopia. Ethiopian Journal of Health Development; 2009 Aug 3;23(1). Available from: http://dx.doi.org/10.4314/ejhd.v2 $\underline{3 i 1.44832}$

20. Ekwueme O, Nwagbo D, Nwobi E. Knowledge and attitude of health workers toward data collection using the health management information system forms at the primary health care $(\mathrm{PHC})$ centers in. Sahel Medical Journal; 2009 Feb 23;11(4). Available from: http://dx.doi.org/10.4314/smi2.v1 $\underline{1 \mathrm{i} 4.12985}$

21. Arabi M, Frongillo EA, Avula R, Mangasaryan N. Infant and Young Child Feeding in Developing Countries. Child Development; 2012 Jan;83(1):32-45. Available from:

http://dx.doi.org/10.1111/j.14678624.2011.01675.x

22. Bylander E. Evidence in Civil Law Sweden. Institut Za Lokalno Samoupravo in Javna Narocila Maribor; 2015; Available from: http://dx.doi.org/10.4335/978961-6842-60-0

23. Delbiso TD. Correlates of Unmet Need for Contraception in Ethiopia: Evidence from 2011 Ethiopian Demographic and Health Survey. African Population Studies; 2014 Aug 6;28(0):989. Available from:

http://dx.doi.org/10.11564/28-0-

$\underline{551}$

24. Shaw KA. Australia?s role in promoting and supporting tuberculosis control in the Western Pacific Region. New South Wales Public Health Bulletin ; 2013;24(1):43. Available from: http://dx.doi.org/10.1071/nb1211 $\underline{9}$

25. Crepinsek MA, Crowe L, Michener $K$, Smart NA. Interventions for preventing mastitis after childbirth. Crepinsek MA, editor. Reviews; 2010 Aug 4; Available from: http://dx.doi.org/10.1002/146518 58.cd007239.pub2

26. Win NN, Binns CW, Zhao $Y$, Scott JA, Oddy WH. International Breastfeeding Journal; 2006;1(1):28. Available from: http://dx.doi.org/10.1186/1746$\underline{4358-1-28}$

27. Papaioannou S, Tzafettas J. Anovulation with or without PCO, hyperandrogenaemia and hyperinsulinaemia as promoters of endometrial and breast cancer. Best Practice \& Research Clinical Obstetrics \& Gynaecology ; 2010 Feb;24(1):19-27. Available from: http://dx.doi.org/10.1016/j.bpobg yn.2008.11.010

28. Johns HM, Forster DA, Amir LH, McLachlan HL. Prevalence and outcomes of breast milk expressing in women with healthy term 
International Journal of Therapeutic Applications, Volume 33, 2016, 72-82

infants: a systematic review. BMC

http://dx.doi.org/10.1186/1471-

Pregnancy and Childbirth; 2013

2393-13-212

Nov 19;13(1). Available from: 
How to cite:

Vancouver:

Ballo TH, Wodajo MZ, SiruMalar J. KNOWLEDGE, ATTITUDE, AND PRACTICES OF EXCLUSIVE BREASTFEEDING: A FACILITY BASED STUDY IN ADDIS ABABA. International Journal of Therapeutic Applications; 2016 Sep 22; 33:72-82. Available from: http://dx.doi.org/10.20530/ijta 33 72-82

APA:

Ballo, T. H., Wodajo, M. Z., \& SiruMalar, J. (2016). KNOWLEDGE, ATTITUDE, AND PRACTICES OF EXCLUSIVE BREASTFEEDING: A FACILITY BASED STUDY IN ADDIS ABABA. International Journal of Therapeutic Applications, 33, 72-82. doi:10.20530/ijta_33_72-82 